УДК 613.6.027

\title{
ГИГИЕНИЧЕСКИЕ АСПЕКТЫ СОСТОЯНИЯ ЗДОРОВЬЯ РАБОТНИКОВ НА ФАРМАЦЕВТИЧЕСКИХ ПРОИЗВОДСТВАХ
}

\author{
Юзбекова Аида Артуровна \\ Кухмазова Алина Теймуровна \\ студенты \\ Научный руководитель: Магомедова Умият Абдулбасировна \\ старший преподаватель кафедры \\ Общей гигиены и экологии человека \\ ФГБОУ ВО «Дагестанский государственный \\ медицинский университет»
}

\begin{abstract}
Аннотация: Исследования последних лет приводят достоверные свидетельства того, что работники фармацевтической промышленности могут подвергаться комплексному воздействию ряда неблагоприятных факторов, в числе которых контакт с аллергенами и химическими веществами, нерациональный микроклимат, пыль, шум, вибрация и другие. Нормативные акты по защите работников от воздействия опасных химических веществ во время работы в определенной степени действуют во всем мире, однако в значительной степени они не соблюдаются в полной мере.

Ключевые слова: химико-фармацевтическое производство, фармакологический эффект, гигиена труда, активный фармацевтический ингредиент.
\end{abstract}

\section{HYGIENIC ASPECTS OF THE HEALTH STATUS OF WORKERS IN PHARMACEUTICAL INDUSTRIES}

\section{Yuzbekova Aida Arturovna Kukhmazova Alina Teimurovna Magomedova Umiyat Abdulbasirovna}

\begin{abstract}
Recent studies provide reliable evidence that pharmaceutical industry workers may be exposed to a number of adverse factors, including contact with allergens and chemicals, irrational microclimate, dust, noise, vibration, and
\end{abstract}


others. Regulations on the protection of workers from exposure to hazardous chemicals during work are to some extent in force all over the world, but to a large extent they are not fully observed.

Key words: chemical and pharmaceutical production, pharmacological effect, occupational hygiene, active pharmaceutical ingredient.

«Разумная гигиена - это, по-видимому, наилучшее средство против ускоренного старения намего организма» Франсуа Мари Бурльер

Химико-фармацевтическая промышленность - это одна из важнейших и высокоотходных отраслей на сегодняшний день. По данным Росстата за 2020 год индекс физического объема по виду экономической деятельности «Производство лекарственных средств и материалов, применяемых в медицинских целях» оказался на уровне $123,2 \%$ по сравнению с предыдущим годом [1].

Лекарственные препараты могут приносить исцеление пациентам различных профилей, но мало кто знает, что процесс их создания оказывает серьезное негативное воздействие на работников фармацевтических производств при недостаточном внимании к личной безопасности. Люди, занимающиеся изготовлением и обработкой таких продуктов, в ходе своей деятельности подвергаются постоянному воздействию активных ингредиентов. Эти ингредиенты предназначены для того, чтобы вызвать различные биологические изменения в организме больного. В условиях производства они оказывают такой же эффект и на здорового фармацевтического работника.

Профессиональный риск является показателем частоты и тяжести неблагоприятных явлений, возникших при воздействии вредных факторов производственной среды. Управление профессиональными рисками находится в центре внимания современных методов охраны труда и техники безопасности, независимо от того, являются ли эти методы нормативными, научными или корпоративными. Оценка профессионального риска - это метод оценки рисков для здоровья, связанных с воздействием различных уровней опасности на рабочем месте. Определение оценки важно для надлежащего устранения, контроля и снижения этих рисков. Оценка риска воздействия вредных веществ, загрязняющих производственную среду, опирается на информацию о токсических свойствах вещества и путях его воздействия на 
человека [2]. Только на основе проведенных токсикологических исследований можно определить параметры вредного воздействия на организм, в отношении которых может даваться заключительная характеристика риска.

Лимитирующий показатель вредности включает три характеристики загрязняющего вещества: относительная токсичность, способность к аккумуляции, устойчивость.

1. Относительная токсичность вещества - определяется как летальная концентрация, приводящая к гибели $50 \%$ особей за определенный период воздействия (ЛК 50$)$.

2. Способность к аккумуляции - характеризуется коэффициентом аккумуляций $\left(\mathrm{K}_{\text {ак }}\right)$, который представляет собой отношение концентрации вредного вещества в объекте или живом организме к концентрации этого же вещества в среде или в пище в равновесном состоянии.

3. Устойчивость к распаду - характеризуется временем снижения концентрации вещества в 20 раз [2].

Относительно недавно в области труда и здравоохранения Организацией Объединенных Наций была введена простая для понимания международная «Глобальная система классификащии, маркировки химических веществ и информирования об опасности с помощью маркировки и паспортов безопасности». Данная система поощряет последовательные, упрощенные сообщения о химических веществах и методах безопасного обращения с ними.

Понимание опасностей и рисков, связанных с медицинскими препаратами, а также доведение соответствующих сообщений о безопасности до работников имеет важное значение.

Основная особенность химико-фармацевтического производства применение большого количества сырья и полупродуктов, представляющих собой химические вещества, каждое из которых является опасным для здоровья и жизни человека. Концентрация полупродуктов и целевых продуктов (собственно лекарственных препаратов) в воздухе рабочей зоны нередко превышает ПДК, особенно во время операций, связанных с разгерметизацией оборудования, загрузкой и выгрузкой сыпучих веществ, отбором технологических проб. Номенклатура этих веществ в основном представлена предельными и непредельными углеводородами, спиртами, кислотами, эфирами и т.д. Токсическое действие почти всех указанных веществ политропно, затрагивает многие физиологические системы: нервную, системы кровообращения и кроветворения, гепатобилиарную $[3,4,5]$. 
Также немаловажным сырьем для синтеза лекарственных средств служат каменный уголь и нефть, из которых получают разнообразные ароматические амины и нитросоединения, фенолы, нафтолы, их сульфокислоты и галогенпроизводные.

Технологический процесс получения синтетических лекарственных средств включает химические реакции, фильтрацию, кристаллизацию, экстракцию, сушку, размол, смешивание, просеивание, развешивание, транспортировку, стандартизацию, фасовку, упаковку [6].

Исследованиями зарубежных и отечественных авторов установлено, что при производстве лекарственных препаратов на работающих, помимо химических веществ, воздействует целый ряд дополнительных факторов: пыль, ультрафиолетовое излучение температура воздуха производственной среды, шум, монотонность труда, напряжения органов зрения. Однако гигиенические характеристики этих факторов разработаны недостаточно [7].

Загрязнение воздуха рабочей зоны пылью наблюдается в основном на подготовительном и заключительном этапах получения лекарственных препаратов. Главными источниками являются доставка исходного сырья из складских помещений в производственные цехи, а также операции, связанные с дроблением, измельчением, просеиванием, транспортировкой и загрузкой. Пыль переносится по воздуху во время производства и является проблемой для операторов. Кроме того, наполнение и упаковка готового продукта могут представлять аллергическую опасность из-за пыли. Помимо пыли в воздухе могут находиться взвешенные химические вещества. Это связано с тем, что по большей части лекарственные средства представляют собой порошки, и любое обращение с порошками может привести к диспергированию их в воздухе [8]. Фармакодинамические данные показывают, что профессиональное воздействие терапевтических веществ, переносимых воздушно-капельным путем, может быть связано с гораздо более высоким риском неблагоприятного воздействия на здоровье, особенно на легкие и кожу, чем при терапевтическом применении. Аналогичным образом, исследования фармакокинетики показывают, что для некоторых терапевтических веществ профессиональное воздействие путем вдыхания приводит к более быстрой и полной системной абсорбции, нежели та же доза, вводимая перорально в терапевтических целях [9]. Патология респираторного тракта в настоящее время одна из наиболее распространенных в профпатологической клинике $[9,10]$. 
Для обеспечения стерильности продукта необходимо постоянно использовать формальдегид. Пары органического соединения при длительном действии в небольших концентрациях способны вызвать жжение в глазах, в носоглотке, аллергический дерматит, крапивницу, головные боли, резкое утомление. Наиболее серьезными последствиями являются рак легких, предстательной железы, лимфогранулематоз (болезнь Ходжкина). При остром воздействии формальдегид приводит к отеку легких и «смертельной пневмонии».

Ультрафиолетовые лампы, также используемые для поддержания стерильности, представляют серьезную проблему. Первыми признаками является сухая, неэластичная, морщинистая кожа. Резко выраженное воздействие УФ-лучей на кожу вызывает дерматиты с диффузной экземой, жжением, зудом и отечностью. Могут развиться различные локализованные кожные язвы («предвестники рака»), которые следует интерпретировать как предупреждающий сигнал.

Таким образом, подробное изучение токсического действия веществ, используемых или получаемых в процессе синтеза лекарственных препаратов, на организм работающих, является важной задачей в области гигиены труда фармацевтических работников. Выбор методов изучения токсического действия полупродуктов при разных путях поступления: через желудочно-кишечный тракт, легкие, кожу, слизистые оболочки обосновывается многими статистическими данными.

Для предупреждения неблагоприятного воздействия на организм работников токсических веществ, пыли лекарственных препаратов необходимы:

- исправно работающая система кондиционирования;

- д достаточное освещение;

- своевременная подача холодной и горячей в воды;

- рациональная система вентиляции, позволяющая своевременно удалять газообразные примеси и пыль из воздуха производственных помещений, не загрязнять воздух административных и бытовых комнат.

А также главным принципом является ограничение уровня действующих неблагоприятных факторов, то есть их гигиеническое нормирование.

В целях исключения вредных последствий воздействия химических веществ на организм человека в России создана система мер медицинского (санитарно-эпидемиологического, санитарно-гигиенического, 
лечебно-профилактического и т. д.) и немедицинского (государственного, общественного, экономического, правового, экологического и др.) характера, направленных на предупреждение несчастных случаев на производстве, снижение риска развития отклонений в состоянии здоровья работников, предотвращение или замедление прогрессирования заболеваний, уменьшение неблагоприятных последствий. Среди них одним из главных является оценка биологической активности химических веществ, ограничение их до безопасных уровней в производственной среде $[9,10]$.

Поэтому для экспериментальной гигиены в области фармацевтической промышленности важным является не только схожесть изучаемой модели к патологии человека, но и информативность, доступность методов оценки патологического процесса и функционального состояния организма животных [11]. Благодаря этому можно проследить медико-биологическое влияние химических соединений на организм, что включает достаточно большой диапазон показателей и оценок, среди которых обязательными являются такие этапы, как установление смертельных эффектов, количественная и качественная характеристика кумулятивных свойств препаратов, изучение кожно-раздражающего, кожно-резорбтивного, сенсибилизирующего действия, установление порогов вредного воздействия.

Медико-гигиеническое регламентирование направлено на обеспечение предупреждения появления заболеваний и, как следствие, создание наиболее комфортных условий жизни и работы. Однако, лишь небольшое число предприятий соблюдают гигиенические регламенты, что обуславливает риск нарушения здоровья и развития профессиональных заболеваний [12].

\section{Заключение.}

Фармацевтическая промышленность является одной из важнейших отраслей промышленности в современном мире, без неё не было бы доступных жизненно важных лекарств. Однако частота заболеваемости многих фармацевтических работников растёт и связано это с многократным воздействием на их организм факторов риска: химические токсические вещества, пыль, шум, ультрафиолетовое излучение, температура помещения, образ жизни работающих... Работник, чья иммунная система ослаблена стрессовой рабочей средой, и чье рабочее место плохо спроектировано с эргономической точки зрения, вполне может понести больший вред от воздействия токсичных химических веществ чем тот, чье единственное воздействие связано с химической опасностью. Кроме того, необходимо 
учитывать многократное химическое и биологическое воздействие, а также повторное или длительное воздействие.

К сожалению, последствия для здоровья, связанные с химическими веществами от работы в фармацевтическом секторе, особенно долгосрочные последствия, вероятно, недооцениваются. Поэтому очень важно внедрять комплексные программы в области охраны труда и обеспечения безопасности работников.

\section{Список литературы}

1. Официальный сайт Федеральной службы государственной статистики/ Электронный ресурс/ Режим доступа https://rosstat.gov.ru/.

2. Пенкиович А.А., Литовилая А.В., Благодатин В.М., Грачева М.П. К проблеме риска нарушения здоровья при воздействии токсических химических веществ //Бюллетень Научного совета «Медико-экологические проблемы работающих». 2004. №4. С. 1517.

3. Захаренков В.В., Горохова Л.Г., Бондарев О.И., Бугаева М.С. Морфологические изменения органов и тканей при субхронической интоксикации препаратами бензодиазепинового ряда (экспериментальные исследования) //Acta biomedica scientifica. 2012. № 52. С. 107112.

4. Халепо А.И. Химическая безопасность и проблемы промышленной токсикологии на современном этапе //Бюллетень Научного совета «Медико-экологические проблемы работающих». 2004. №3. С. 2935.

5. Кузьмин С.В., Привалова Л.И., Кацнельсон Б.А. и др. Оценка риска и экологическая эпидемиология: сборник инструктивно-методических документов. Екатеринбург, 2000. 204 с.

6. Бурак И.И., Юркевич А.Б., Миклис Н.И. Фармацевтическая гигиена: пособие для студентов учреждений высшего образования, обучающихся по специальности 1-79 0108 "Фармация" / Опубликовано: Витебск : ВГМУ, 2018.

7. Джангозина Д.М, Темиреева К.С., Л Лман.ясол И.А., Абдуллабекова Р.М., Тукубаева Г.Н., Перепичко Н.З., Ивлева Л.П., Ахметова А.Ж., Дербуш С.Н., Кудеринова М.К. Факторы производственной деятельности, влияющие на условия труда фармацевтических работников // Международный журнал экспериментального образования, 2009. № 3. С. 31-36.

8. Agius R (1989) Occupational Exposure limits for therapeutic substances. Ann Occup Hyg 33: 555-562. 4. 
9. Полякова И.Н. Актуальные вопросы профессиональных заболеваний легких и перспективные направления исследований //Медицина труда и промышленная экология. 2007. № 7. С. 1.

10. Ader A.W., Kimmel T.A., Sussman R.G. (2009) Applying health-based risk assessments to worker and product safety for potent pharmaceuticals in contract manufacturing operations. Pharmaceutical Outsourcing 48-53.

11. Соседова Л.М., Якимова Н.Л., Капустина Е.А., Титов Е.А. Экспериментальное моделирование токсической энцефалопатии //Медицина труда и промышленная экология. 2008. № 8. С. 22-26.

12. Рембовский В.Р., Могиленкова Л.А. Классификация состояния здоровья работающих при воздействии химического фактора // Медицина труда и промышленная экология. 2006. № 11. С. 25-31. 